\title{
Unplanned readmission or death after discharge for Aboriginal and non- Aboriginal people with chronic disease in NSW Australia: a retrospective cohort study
}

Amanda Jayakody ${ }^{1,2,3^{*}}$ (D), Christopher Oldmeadow ${ }^{4,5}$, Mariko Carey ${ }^{1,2,3}$, Jamie Bryant ${ }^{1,2,3}$, Tiffany Evans ${ }^{4,5}$, Stephen Ella ${ }^{6}$, John Attia ${ }^{4,5}$ and Rob Sanson-Fisher ${ }^{1,2,3}$

\begin{abstract}
Background: Admitted patients with chronic disease are at high risk of an unplanned hospital readmission, however, little research has examined unplanned readmission among Aboriginal people in Australia. This study aimed to examine whether rates of unplanned 28 day hospital readmission, or death, significantly differ between Aboriginal and non-Aboriginal patients in New South Wales, Australia, over a nine-year period.

Methods: A retrospective cohort analysis of a sample of de-identified linked hospital administrative data was conducted. Eligible patients were: 1) aged $\geq 18$ years old, 2) admitted to an acute facility in a NSW public hospital between 30th June 2005 and 1st July 2014, and 3) admitted with either cardiovascular disease, chronic respiratory disease, diabetes or renal disease. The primary composite outcome was unplanned readmission or death within 28 days of discharge. Generalized linear models and a test for trend were used to assess rates of unplanned readmission or death over time in Aboriginal and non-Aboriginal patients with chronic disease, accounting for sociodemographic variables.

Results: The final study cohort included 122,145 separations corresponding to 48,252 patients (Aboriginal $=57.2 \%$, $n=27,601$; non-Aboriginal $=42.8 \%, n=20,651) .13 .9 \%(n=16,999)$ of all separations experienced an unplanned readmission or death within 28 days of discharge. Death within 28 days of discharge alone accounted for only a small number of separations $(1.4 \% ; n=1767)$. Over the nine-year period, Aboriginal separations had a significantly higher relative risk of an unplanned readmission or death (Relative risk = $1.34(1.29,1.40)$; $p$-value $<0.0001)$ compared with non-Aboriginal separations once adjusted for sociodemographic, disease variables and restricted to $<75$ years of age. A test for trend, including an interaction between year and Aboriginal status, showed there was no statistically significant change in proportions over the nine-year period for Aboriginal and non-Aboriginal separations ( $p$-value for trend $=0.176)$.

Conclusion: Aboriginal people with chronic disease had a significantly higher risk of unplanned readmission or death 28 days post discharge from hospital compared with non-Aboriginal people, and there has been no significant change over the nine year period. It is critical that effective interventions to reduce unplanned readmissions for Aboriginal people are identified.
\end{abstract}

Keywords: Aboriginal health, Unplanned readmission, Health services research, Data linkage, Chronic disease

\footnotetext{
* Correspondence: amanda.jayakody@uon.edu.au

${ }^{1}$ Health Behaviour Research Collaborative, School of Medicine and Public

Health, Faculty of Health and Medicine, University of Newcastle, Callaghan,

NSW 2308, Australia

${ }^{2}$ Priority Research Centre for Health Behaviour, University of Newcastle,

Callaghan, NSW, Australia

Full list of author information is available at the end of the article
}

(c) The Author(s). 2018 Open Access This article is distributed under the terms of the Creative Commons Attribution 4.0 International License (http://creativecommons.org/licenses/by/4.0/), which permits unrestricted use, distribution, and reproduction in any medium, provided you give appropriate credit to the original author(s) and the source, provide a link to the Creative Commons license, and indicate if changes were made. The Creative Commons Public Domain Dedication waiver (http://creativecommons.org/publicdomain/zero/1.0/) applies to the data made available in this article, unless otherwise stated. 


\section{Background}

On average Aboriginal and Torres Strait Islander people (Aboriginal people hereafter) ${ }^{1}$ experience, on average, a 10 year gap in life expectancy compared with non-Aboriginal Australians. Two thirds of this gap is accounted for by chronic disease [1]. Chronic diseases in Aboriginal people are both more prevalent and occur at a much younger age[1, 2]. Aboriginal people have higher self-reported rates of cardiovascular disease, respiratory disease, diabetes and renal disease than non-Aboriginal people $[1,2]$.

Although most chronic diseases should ideally be managed in the community health setting, admissions to hospital related to chronic disease are common and represent the largest proportion of potentially avoidable hospitalisations [3]. Factors such as poor discharge planning, poor community follow up from health care services, and a lack of support for the patient and carer in chronic disease self-management skills mean that many hospital admissions for chronic disease are followed by an unplanned hospital readmission [4-8]. Unplanned readmissions are defined as admissions to hospital which were not planned and which usually occur within one month of discharge from an initial (i.e. index) admission $[9,10]$. Unplanned readmissions are a financial burden to the health system, and cause an emotional and time burden on patients and their families [11, 12]. Admitted patients with chronic disease are known to be at high risk of an unplanned hospital readmission, with readmission highest amongst patients with cardiovascular disease, respiratory disease and diabetes $[11,13,14]$. In the Australian state of New South Wales (NSW) 13\% of patients with COPD and $9 \%$ of patients with CHF were readmitted within 28 days [3]. In Australia, unplanned readmissions are considered an indicator relating to "high quality and affordable hospital and hospital related care" in the Australian National Healthcare Agreement, and unplanned readmissions are included in the NSW service performance indicators to provide a mechanism for monitoring and managing the performance of hospitals $[9,15]$.

However there is limited knowledge of the rate of unplanned readmission for Aboriginal people with chronic disease. In a NSW Chief Health Officer's report on the health of Aboriginal people of NSW, the all-cause (all medical and surgical) unplanned readmission rate within 28 days for Aboriginal people was 8.1\% (compared with $6.3 \%$ for non-Aboriginal people) [9]. The all-cause readmission rate has remained consistently higher for Aboriginal people [9]. However little is known regarding the patterns over time for unplanned readmissions amongst Aboriginal people with chronic disease. An analysis of readmission rates within one regional western NSW hospital found the proportion of Aboriginal patients readmitted to hospital had increased from $11.7 \%$ in 1996 to $18.3 \%$ in 2005 , however there was no significant trend over time
[16]. This analysis did not look specifically at trends in chronic diseases for Aboriginal patients, and the data may not be representative of NSW Aboriginal people as a whole.

Given the high burden of chronic disease and high rates of unplanned readmission rates among Aboriginal people, there is a need for more specific analysis of unplanned readmissions related to chronic disease in order to identify potential differences and patterns amongst Aboriginal and non-Aboriginal people over time. The purpose of our study was to examine amongst Aboriginal and non-Aboriginal people with chronic disease in NSW from 2005/6 to 2014/15: 1) whether the proportion of separations with an unplanned 28 day readmission or death significantly differ between Aboriginal and non-Aboriginal patients; 2) the extent to which sociodemographic, disease and separation factors are associated with any differences; and 3) how the proportion of separations with an unplanned 28 day hospital readmission or death changed over the nine-year period.

\section{Methods}

\section{Ethics approval}

The study was approved by the NSW Population \& Health Services Research Ethics Committee (HREC/15/ CIPHS/18) and the NSW Aboriginal Health and Medical Research Council Ethics Committee (1090/15).

\section{Study design and data sources}

This study was a retrospective cohort analysis of deidentified linked hospital administrative data. The linked data were derived from three datasets:

1) NSW Admitted Patient Data Collection (APDC): the APDC contains records of all admitted patient services provided by NSW public hospitals, private hospitals/centres and psychiatric hospitals.

2) NSW Emergency Department Data Collection (EDDC): the EDDC contains records for patient presentations to emergency departments in NSW public hospitals.

3) NSW Registrar of Births, Deaths and Marriages (RBDM): the RBDM contains mortality information for the NSW population.

\section{Study sample \\ Eligibility criteria}

The study sample included patients who were: 1) aged 18 years and older at the time of admission; 2 ) admitted to an acute facility in a NSW public hospital between 30th June 2005 and 1st July 2014; 3) discharged from hospital to the community; and 4) had one or more of the following ICD-10 defined chronic diseases as a principle 
or additional diagnosis: cardiovascular disease, diabetes, respiratory disease and renal diseases (See Additional file 1 for a list of ICD-10 codes). Figure 1 outlines how the dataset was generated.

\section{Sampling}

All patients meeting the eligibility criteria who had at least one APDC separation in the period of interest, and where status was recorded as Aboriginal and/or Torres Strait Islander person on any APDC record were selected. In order to obtain a comparison sample of non-Aboriginal persons, a sampling frame was then generated consisting of a list of patients meeting the eligibility criteria recorded in the APDC, excluding the list of Aboriginal persons obtained above. A random sample of person identification numbers (of the same number as the Aboriginal cases) was selected from the sampling frame, forming the
non-Aboriginal patient sample. These patients had no APDC records with Aboriginality coded as 'yes'. EDDC and RBDM death records which linked to the patients were extracted and included in the final sample.

\section{Data linkage}

The data sources were linked by the Centre for Health Record Linkage using probabilistic record linkage methods [17]. All data were provided in a de-identified format. The data were supplied as episodes of care. Each episode of care ends with a statistical discharge; each statistical discharge occurs due to discharge, death, transfer, or change of care type.

\section{Data cleaning}

Duplicate records were excluded. Separations were defined by combining nested, overlapping and contiguous

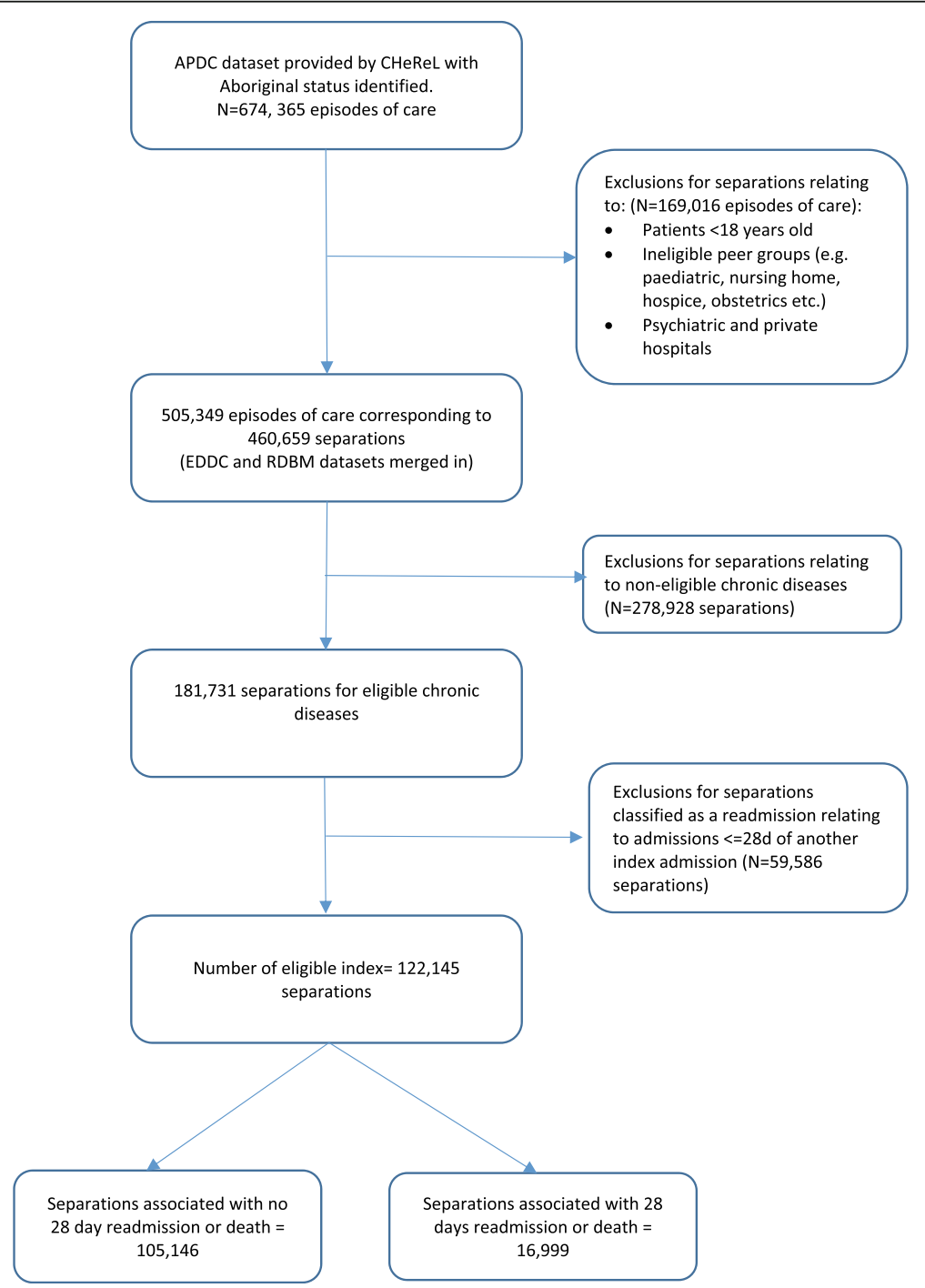

Fig. 1 Flow diagram of dataset generation 
episodes of care creating periods for which patients were hospitalised. Therefore separations are defined as the total hospital stay (from admission to discharge from hospital). For our analyses we retained the diagnosis codes and admission data from the first episode of each separation, but our discharge date, from which 28 day readmission or death is considered, was the latest discharge date for the period of hospitalisation. The unit of analysis was separations.

\section{Variables}

Primary outcome: The primary composite outcome was all-cause unplanned hospital readmission or death within 28 days of separation from any acute facility in a NSW public hospital. An unplanned readmission is defined as occurring within 28 days of discharge from an initial (i.e. index) admission. 'Unplanned' refers to separations coded as an 'emergency status recode' in the APDC. Readmissions due to mental health, cancer, hospital in home care, chemotherapy or dialysis were excluded. Separations were excluded if death occurred during admission or if the patient was discharged to palliative care. Sensitivity analyses were conducted to examine the effect of deaths or discharge to palliative care during admission which is described in the statistical analysis section. Each subsequent separation that fell outside of the 28 day timeframe was counted as a new index separation (see Fig. 1). All-cause readmission or death was calculated as follows: Numerator: total number of 28 day unplanned readmission or death for any cause associated with an eligible index admission. Denominator: number of admissions with an included chronic disease (principal or additional diagnosis) and an index admission.

\section{Explanatory variables}

The following explanatory variables correspond to those recorded at the beginning of each separation.

1. Sociodemographic variables: Patient's gender, age, Aboriginal status and marital status. The Accessibility/Remoteness Index of Australia (ARIA) and the Index of Relative Socio-economic Disadvantage (IRSD) quintile were also included. ARIA is the standard Australian Bureau of Statistics (ABS) endorsed measure of remoteness and is derived from measures of road distances between populated localities and service centres [18]. The IRSD is a general socio-economic index that summarises a range of information about the economic and social conditions of people and households within a geographic area [19].

2. Disease-related variables: the Charlson Co-morbidity Index (CCI) was included [20]. The CCI is an index of the risk of mortality from comorbidity during the next 12 months and calculates a score from secondary diagnoses of admissions weighted for type of condition. The CCI scores were dichotomised into three groups of 0,1 and 2 or more. Zero indicating the lowest score and 2 or more indicating the highest scores.

3. Separation variables: The following variables were included for each hospital separation: financial year of separation and length of stay (days).

\section{Statistical analysis}

Chi-square and t-tests were used to examine crude associations between Aboriginal status and sociodemographic, disease and separation factors. A log-binomial generalised linear model (GLM) was used to determine the association between Aboriginal status and unplanned readmission or death over the nine year period, and then restricted to patients aged $\leq 75$ years due to the differential age structures between Aboriginal and non-Aboriginal patients. Exponentiated parameter estimates from this model (interpreted as relative risks) are presented together with 95\% confidence intervals and $p$-values. A propensity score analysis was conducted to account for potential selection bias due to differences in the probability of dying during admission to hospital between Aboriginal and non-Aboriginal people [21]. The propensity score was estimated using a logistic regression model (death in hospital or discharged to palliative care as the outcome, sociodemographic, disease and separation factors as predictors), and stabilised propensity scores were used as weights (inverse probability of "treatments") in the GLM. Unplanned readmission or death within 28 days trends over the study period were assessed by including a term for financial year (as a continuous variable) in the GLM, as well as an interaction term between Aboriginal status and year, which assessed differences in the trends by Aboriginal status. The model was adjusted for sociodemographic and disease variables. A sensitivity analysis was conducted to examine any potential differences in results obtained using an all-cause compared to a chronic disease specific readmission rate. All analyses used Stata V.11.2 [22].

\section{Results}

In the linked dataset there were 674, 365 hospital episodes of care for Aboriginal and non-Aboriginal patients. After separations not meeting inclusion criteria were excluded, the final study cohort included 122,145 separations (Aboriginal $=77,427$; Non-Aboriginal $=44,718)$, corresponding to 48,252 patients (Aboriginal $=57.2 \%, n=27,601$; nonAboriginal $=42.8 \%, n=20,651$ ). Table 1 describes the characteristics of separations by Aboriginal status. Aboriginal separations were significantly younger and had a 
Table 1 Characteristics of separations by Aboriginal status ( $n=122,145$ )

\begin{tabular}{|c|c|c|c|c|}
\hline & & $\begin{array}{l}\text { Aboriginal }(n=77,427) \\
n(\%)\end{array}$ & $\begin{array}{l}\text { Non-Aboriginal }(n=44,718) \\
n(\%)\end{array}$ & $p$-value \\
\hline Sex & $\%$ Female & $42,982(55.5)$ & $22,422(50.1)$ & $>0.001$ \\
\hline Age & Mean (SD) & $53.5(16.5)$ & $66.7(17.9)$ & $>0.001$ \\
\hline \multirow[t]{5}{*}{ Marital status } & Married/de facto & $30,992(40.1)$ & $23,815(53.3)$ & \multirow[t]{5}{*}{$>0.001$} \\
\hline & Single & $25,178(32.5)$ & $5673(12.7)$ & \\
\hline & Widowed & $9385(12.1)$ & $9884(22.1)$ & \\
\hline & Divorced/separated & $10,434(13.5)$ & $4720(10.6)$ & \\
\hline & Not known & $1372(1.8)$ & $592(1.3)$ & \\
\hline \multirow[t]{4}{*}{ Chronic diseases present at admission } & Diabetes & $32,865(39.5)$ & $11,853(26.5)$ & $>0.001$ \\
\hline & Chronic respiratory disease & $15,403(19.9)$ & $6135(13.7)$ & $<0.0001$ \\
\hline & Cardiovascular disease & $41,977(54.2)$ & $29,231(65.4)$ & $<0.0001$ \\
\hline & Renal disease & $20,133(26.0)$ & $12,638(28.3)$ & $<0.0001$ \\
\hline \multirow[t]{3}{*}{ Charlson Co-morbidity Index score } & 0 & $43,888(56.7)$ & $25,454(56.9)$ & \multirow[t]{3}{*}{$<0.0001$} \\
\hline & 1 & $18,835(24.3)$ & $9979(22.3)$ & \\
\hline & $2+$ & $14,704(19.0)$ & $9285(20.8)$ & \\
\hline \multirow[t]{5}{*}{ IRSD } & 1st quintile - most disadvantaged & $19,505(25.2)$ & $5823(13.0)$ & \multirow[t]{5}{*}{$<0.0001$} \\
\hline & 2nd quintile & $22,584(29.2)$ & $10,529(23.6)$ & \\
\hline & 3rd quintile & $16,701(21.6)$ & $8788(19.7)$ & \\
\hline & 4th quintile & $14,286(18.5)$ & $9985(22.3)$ & \\
\hline & 5th quintile - least disadvantaged & $4351(5.6)$ & $9593(21.4)$ & \\
\hline \multirow[t]{4}{*}{ ARIA } & Highly Accessible (major cities) & 29,855 (38.6) & $31,521(70.5)$ & \multirow[t]{4}{*}{$<0.0001$} \\
\hline & Accessible (inner regional) & $29,132(37.6)$ & $10,348(23.1)$ & \\
\hline & Moderately Accessible (outer regional) & $13,692(17.7)$ & $2560(5.7)$ & \\
\hline & Remote / Very Remote & $4748(6.1)$ & $289(0.7)$ & \\
\hline \multirow[t]{9}{*}{ Year of separation } & $2005-06$ & $7547(10.3)$ & $4680(11.2)$ & \multirow[t]{9}{*}{$<0.0001$} \\
\hline & 2006-07 & $7840(10.7)$ & $4719(11.3)$ & \\
\hline & 2007-08 & $7980(10.9)$ & $4693(11.2)$ & \\
\hline & 2008-09 & $6905(9.5)$ & $4143(9.9)$ & \\
\hline & 2009-10 & $7041(9.6)$ & $4169(10.0)$ & \\
\hline & 2010-11 & $7010(9.6)$ & $4061(9.7)$ & \\
\hline & $2011-12$ & $7807(10.7)$ & $4343(10.4)$ & \\
\hline & $2012-13$ & $10,243(14.0)$ & $5391(12.9)$ & \\
\hline & 2013-14 & $10,643(14.6)$ & $5644(13.5)$ & \\
\hline Length of stay (days) & Mean (SD) & $5.6(14.2)$ & $6.9(17.2)$ & $<0.0001$ \\
\hline
\end{tabular}

higher proportion of female separations, compared with non-Aboriginal separations. A smaller proportion of Aboriginal separations corresponded to individuals who were married or in a de facto relationship compared with non-Aboriginal separations. Compared to non-Aboriginal separations, there were a higher proportion of separations associated with diabetes and chronic respiratory disease among Aboriginal separations. Cardiovascular disease was significantly higher amongst non-Aboriginal separations and is evidenced in the higher Charlson comorbidity index which gives greater weight to cardiovascular disease. A higher proportion of Aboriginal separations correspond to individuals residing in the most disadvantaged geographic and remote/very remote areas of NSW. Aboriginal separations had a lower average length of stay compared with non-Aboriginal separations.

$13.9 \%$ ( $n=16,999)$ of all separations experienced an unplanned readmission or death within 28 days of discharge. Death within 28 days of discharge accounted for only a small number of separations overall (1.4\%; $n=1767)$. An unadjusted regression, demonstrated that Aboriginal separations had a significantly higher risk of an unplanned 
readmission or death within 28 days of discharge compared with non-Aboriginal separations (Table 2; Relative risk $(\mathrm{RR})=1.16$; 95\% confidence intervals $(\mathrm{CI}): 1.13,1.19$; $p$-value: <0.0001). To account for the younger age distribution in Aboriginal people compared with nonAboriginal people, the model was restricted to people aged $<75$ years old. This resulted in the relative risk increasing to 1.36 (95\% CI:1.30, 1.41; $p$-value: < 0.0001). A sensitivity analysis, was conducted to examine any potential differences between using an all-cause compared to a chronic disease specific readmission rate, and results were broadly similar.

\section{Propensity score weighted analyses}

Aboriginal people were significantly less likely to die during admission or be discharged to palliative care compared with non-Aboriginal people (Odds ratio $=0.73 ; 95 \% \mathrm{CI}$ : $0.68,0.79 ;<0.001$; $\mathrm{AUC}=0.7714$; pseudo $\mathrm{R} 2=0.1096$ ). Sample weights were created using a stabilised propensity score to account for the potential selection bias due to the difference in probability of dying during admission. The propensity score sample weight was included in the following regression analyses whilst separations which ended in death during admission or the patient being discharged to palliative care were excluded from the analysis $(2.84 \%$, $n=3570)$.

\section{Adjusted regression analyses}

Table 3 shows the unadjusted and adjusted regression models examining the effect of sociodemographic and disease variables on the association of Aboriginal status and unplanned readmission or death. Aboriginal separations continued to have a significantly higher risk of an unplanned readmission or death compared with non-Aboriginal separations once adjusted for sociodemographic (including the age restriction) and disease variables, including the propensity score sampling weight $(\mathrm{RR}=1.34 ; \mathrm{CI}: 1.29,1.40 ; p<0.0001)$. Length of stay was not included in the final model because of the direction of its relationship with Aboriginal status and readmission. Although it was associated with both Aboriginal status and readmission, a sensitivity analysis including length of stay in the adjusted model showed that the overall results were broadly similar. Apart from financial year, all sociodemographic and disease variables remained significantly associated with readmission after controlling for all variables in the table.

Figure 2 displays the raw proportions and predicted probabilities (obtained from the final GLM model shown in Table 4) of unplanned readmission or death by Aboriginal status. There was no statistically significant change in the proportion of separations that resulted in an unplanned readmission or death over the nine-year period for Aboriginal and non-Aboriginal separations ( $p$-value for trend $=0.176$ ). The apparent gap between the fitted values and raw proportions are due to the fact that the fitted values are adjusted for sociodemographic variables.

\section{Discussion}

This paper provides unique data on unplanned hospital readmission or death over a nine year period amongst a large cohort of Aboriginal and non-Aboriginal patients with chronic disease. To our knowledge, such an overview of unplanned readmission by Aboriginal people with chronic disease has not been undertaken before in Australia.

Aboriginal people with chronic disease have a significantly higher risk of an unplanned readmission or death within 28 days of discharge compared with non-Aboriginal people. This higher rate of unplanned readmission or death has remained unchanged over the nine year period examined. Direct comparisons of our estimates with other studies are challenging because of a paucity of comparable data analyses for unplanned readmissions in Aboriginal Australians with chronic disease. However when considering readmissions for any-cause, our findings are consistent with NSW government data which reports significantly higher rates of all-cause (medical and surgical) unplanned readmissions rates between Aboriginal and non-Aboriginal people, and that this rate has not significantly changed from 2005 to 2011 [9]. However the chronic disease readmission rates reported in our analysis are higher compared to readmissions for any cause. Our findings are consistent with other broader analyses of hospitalisation patterns among Aboriginal people with chronic disease which also report significantly higher rates of unavoidable or potentially preventable hospitalisations in Aboriginal with chronic disease compared with non-Aboriginal people [23, 24]. Yet these studies do not consider unplanned readmissions which measure a distinctly different indicator compared to unavoidable

Table 2 Differences in separations that resulted in an unplanned readmission or death by Aboriginal status, for the period 2005/ 6-2013/14

\begin{tabular}{|c|c|c|c|c|}
\hline & \multicolumn{2}{|c|}{ Unplanned readmission or death $(n=122,145)$} & \multirow{2}{*}{$\begin{array}{l}\text { Unadjusted relative risk } \\
\text { (RR), (95\% Cl; } P \text {-value) }\end{array}$} & \multirow{2}{*}{$\begin{array}{l}\text { RR restricted to patients } \\
\text { aged }<75 \text { yrs., }(95 \% \mathrm{Cl} ; \\
P \text {-value) }\end{array}$} \\
\hline & Yes & No & & \\
\hline Aboriginal $n(\%)$ & $11,349(14.7)$ & $66,078(85.3)$ & $1.16(1.13,1.19 ;<0.0001)$ & $1.36(1.30,1.41 ;<0.0001)$ \\
\hline Non-Aboriginal $n(\%)$ & $5650(12.6)$ & $39,068(87.4)$ & ref & ref \\
\hline
\end{tabular}


Table 3 Unadjusted and adjusted GLM regression models of unplanned readmission or death by Aboriginal status for the study period 2005/6 to 2013/14

\begin{tabular}{|c|c|c|c|c|}
\hline $\begin{array}{l}\text { Unplanned readmiss } \\
\text { Relative risks (RR) (95 }\end{array}$ & $\begin{array}{l}\text { on or death } \\
\% \mathrm{Cl})\end{array}$ & & & \\
\hline $\begin{array}{l}\text { Unadjusted RR with } \\
\text { propensity score } \\
\text { (PS) weight }\end{array}$ & $\begin{array}{l}\text { Unadjusted RR } \\
\text { without PS weight }\end{array}$ & $\begin{array}{l}\text { Adjusted }^{\mathrm{a}} \mathrm{RR} \\
\text { with PS weight }\end{array}$ & $\begin{array}{l}\text { Adjusted }^{\mathrm{a}} \text { RR } \\
\text { without PS weight }\end{array}$ & $\begin{array}{l}\text { Adjusted }^{a} \text { RR with PS } \\
\text { weight and restricted } \\
\text { to }<75 \text { years }\end{array}$ \\
\hline
\end{tabular}

\begin{tabular}{|c|c|c|c|c|c|c|}
\hline \multirow{2}{*}{\multicolumn{7}{|c|}{ Aboriginal status }} \\
\hline & & & & & & \\
\hline Non-Aboriginal & ref & ref & ref & Ref & \multicolumn{2}{|l|}{ red } \\
\hline Aboriginal & $1.15(1.12,1.19)$ & $1.16(1.13,1.20)$ & $1.29(1.24,1.33)$ & $1.29(1.24,1.33)$ & $1.34(1.29,1.40)$ & $<0.0001$ \\
\hline Year & $1.00(0.99,1.01)$ & $1.00(0.99,1.01)$ & $1.00(0.99,1.01)$ & $1.00(0.99,1.01)$ & $1.00(0.99,1.01)$ & 0.529 \\
\hline Gender & - & - & - & & & \\
\hline Male & - & - & ref & ref & ref & \\
\hline Female & - & - & $0.89(0.86,0.92)$ & $0.89(0.86,0.91)$ & $0.87(0.84,0.90)$ & $<0.0001$ \\
\hline Age & - & - & $1.01(1.01,1.01)$ & $1.01(1.01,1.01)$ & $1.01(1.00,1.01)$ & $<0.0001$ \\
\hline Marital status & - & - & & & & \\
\hline Married & - & - & ref & ref & ref & \\
\hline Single & - & - & $1.19(1.15,1.24)$ & $1.20(1.15,1.24)$ & $1.20(1.15,1.25)$ & $<0.0001$ \\
\hline Widowed & - & - & $1.18(1.13,1.23)$ & $1.18(1.13,1.23)$ & $1.21(1.13,1.28)$ & $<0.0001$ \\
\hline Divorced/separated & - & - & $1.15(1.10,1.20)$ & $1.15(1.10,1.20)$ & $1.18(1.12,1.24)$ & $<0.0001$ \\
\hline Not known & - & - & $0.92(0.81,1.05)$ & $0.93(0.82,1.06)$ & $0.97(0.84,1.12)$ & 0.685 \\
\hline \multicolumn{7}{|l|}{ IRSD } \\
\hline 1st quintile - most disadvantaged & - & - & ref & ref & ref & \\
\hline 2nd quintile & - & - & $0.94(0.90,0.98)$ & $0.94(0.90,0.98)$ & $0.94(0.90,0.99)$ & $<0.05$ \\
\hline 3rd quintile & - & - & $0.94(0.90,0.99)$ & $0.94(0.90,0.99)$ & $0.93(0.88,0.98)$ & $<0.05$ \\
\hline 4th quintile & - & - & $0.93(0.88,0.98)$ & $0.93(0.88,0.98)$ & $0.94(0.88,0.99)$ & $<0.05$ \\
\hline 5th quintile - least disadvantaged & - & - & $0.88(0.83,0.94)$ & $0.88(0.83,0.94)$ & $0.80(0.74,0.87)$ & $<0.0001$ \\
\hline \multicolumn{7}{|l|}{ ARIA } \\
\hline Highly Accessible & - & - & ref & ref & ref & \\
\hline Accessible & - & - & $0.93(0.89,0.96)$ & $0.93(0.89,0.96)$ & $0.93(0.90,0.97)$ & $>0.01$ \\
\hline Moderately Accessible & - & - & $0.87(0.84,0.93)$ & $0.87(0.84,0.93)$ & $0.87(0.82,0.92)$ & $<0.0001$ \\
\hline RemoteNery Remote & - & - & $0.67(0.61,0.73)$ & $0.67(0.61,0.73)$ & $0.65(0.59,0.72)$ & $<0.0001$ \\
\hline \multicolumn{7}{|l|}{ Charlson Index score } \\
\hline 0 & - & - & ref & ref & ref & \\
\hline 1 & - & - & $1.43(1.38,1.48)$ & $1.43(1.38,1.48)$ & $1.45(1.39,1.51)$ & $<0.0001$ \\
\hline $2+$ & - & - & $1.63(1.57,1.69)$ & $1.63(1.57,1.69)$ & $1.69(1.62,1.77)$ & $<0.0001$ \\
\hline
\end{tabular}

${ }^{\mathrm{a} R \mathrm{R} s}$ are adjusted for all variables given in the table

hospitalisations which generally reflects sub-optimal community health care, compared to unplanned readmissions which reflect a combination of poor hospital care as well as poor community follow up.

Our findings showed that unplanned readmission or death in Aboriginal people remained significantly higher than the non-Aboriginal rates, even once adjusted for sociodemographic, disease and admission variables, and for potential selection bias. The fact that Aboriginal status remains a significant risk factor, even after accounting for other variables, is consistent with chronic disease preventable hospitalisation studies in
Aboriginal people, $[23,25]$ and the international literature which shows significant associations with ethnicity and readmission even after adjusting for sociodemographic or disease factors [26-28]. However considering the sociodemographic profile of Aboriginal patients with chronic disease is informative for program planning. Our study found a higher proportion of Aboriginal patients were female, younger, more likely to be single, live in the most disadvantaged and remote areas of NSW. This difference in socio-demographic profile should be considered in strategies aimed at reducing unplanned readmissions in Aboriginal people with chronic disease. 


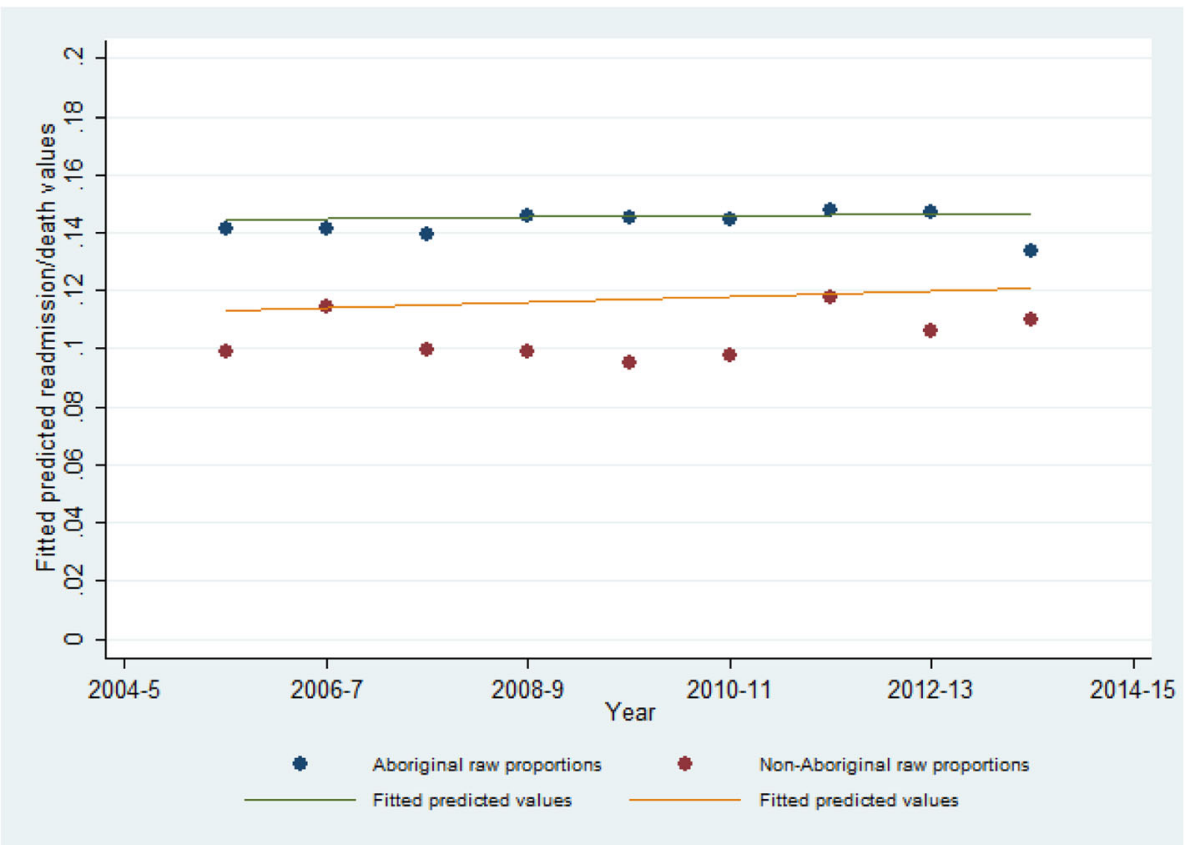

Fig. 2 Trend analysis for unplanned readmission or death calculated for each year of the study period (2005-6 to 2013-14) by Aboriginal status

The fact that the significant difference in readmission or death rates has consistently remained over the nine years highlights the ongoing disparity between Aboriginal and non-Aboriginal health outcomes. Therefore, further targeted programs need to address the gap in effective care for high risk Aboriginal patients with chronic disease. The high prevalence of chronic diseases among patients, particularly the presence of multiple comorbidities in adults, requires intensive case management in both hospital and community settings, to ensure follow up post discharge is adequately conducted [29]. Qualitative work on the effectiveness of discharge planning and post-acute care for Aboriginal patients in improving health outcomes such as readmission, suggests good outcomes are dependent on the availability, knowledge and use of post-acute services and better access to primary health care [30]. One current NSW Health program targets Aboriginal patients recently discharged from hospital with a chronic disease and provides telephone follow-up within $48 \mathrm{~h}$. It demonstrated a significant decrease in emergency department presentations, but not in unplanned readmissions, in Aboriginal people who received the follow up compared with eligible Aboriginal people who did not [31]. Further research is needed to determine the types of interventions that are effective in reducing unplanned readmissions in Aboriginal people with chronic disease.

Our finding that length of stay was shorter for Aboriginal people compared to non-Aboriginal differs to other studies. Banham and colleagues in their study of potentially preventable hospitalisations in Aboriginal people with chronic disease report higher length of stay compared to non-Aboriginal people [23]. Although shorter length of stay is often considered more efficient, it may indicate either a higher risk of discharge against medical advice in this group of patients, or that they are not receiving the sufficient care resulting in poorer health outcomes and increased risk of readmission $[32,33]$. Further research should investigate length of stay in Aboriginal people with chronic disease.

\section{Limitations}

Study findings should be considered in light of several limitations. There may be an underrepresentation in unplanned readmission rates due to underreporting of Aboriginality in hospital data, and therefore caution is needed in interpreting all hospital-level data for Aboriginal people. Further, not all data on non-Aboriginal separations is included in this analysis, only a sample of non-Aboriginal separations were included who met the eligibility criteria (compared to all Aboriginal cases where all cases meeting the criteria were selected). Therefore it is possible that the non-Aboriginal sample is not representative of all non-Aboriginal people meeting the study eligibility criteria.

We could not exclude the possibility that a selection bias was induced through selecting only those that survived the admission. Our propensity score analysis attempted to resolve this by weighting the analysis 
Table 4 Testing for a trend over time in unplanned readmission or death: Unadjusted and adjusted GLM regression models of unplanned readmission or death by Aboriginal status including an interaction term for year and Aboriginal status (2005/6 to 2013/14)

\begin{tabular}{|c|c|c|c|c|c|c|}
\hline & \multicolumn{6}{|c|}{$\begin{array}{l}\text { Unplanned readmission or death with interaction term } \\
\text { Relative risks (RR) }(95 \% \mathrm{Cl})\end{array}$} \\
\hline & $\begin{array}{l}\text { Unadjusted RR with } \\
\text { propensity score } \\
\text { (PS) weight }\end{array}$ & $\begin{array}{l}\text { Unadjusted RR } \\
\text { without PS weight }\end{array}$ & $\begin{array}{l}\text { Adjusted }^{\mathrm{a}} \mathrm{RR} \\
\text { with PS weight }\end{array}$ & $\begin{array}{l}\text { Adjusted }^{a} \text { RR } \\
\text { without PS weight }\end{array}$ & $\begin{array}{l}\text { Adjusted }^{\mathrm{a}} \text { RR with } \\
\text { PS weight and } \\
\text { restricted to }<75 \text { years }\end{array}$ & $P$-value \\
\hline \multicolumn{7}{|l|}{ Aboriginal status } \\
\hline Non-Aboriginal & ref & ref & ref & Ref & red & \\
\hline Aboriginal & $1.15(1.11,1.19)$ & $1.16(1.12,1.20)$ & $1.28(1.23,1.32)$ & $1.28(1.23,1.33)$ & $1.33(1.27,1.39)$ & $<0.0001$ \\
\hline Year & $1.00(0.99,1.01)$ & $1.00(0.99,1.01)$ & $1.00(0.99,1.01)$ & $0.99(0.99,1.01)$ & $1.01(0.99,1.02)$ & 0.140 \\
\hline \multicolumn{7}{|l|}{ Interaction term } \\
\hline Year and Aboriginal status & $1.00(0.99,1.02)$ & $1.01(0.99,1.02)$ & $1.01(0.99,1.02)$ & $1.01(1.00,1.02)$ & $0.99(0.97,1.00)$ & 0.176 \\
\hline Gender & - & - & - & & & \\
\hline Male & - & - & ref & ref & ref & \\
\hline Female & - & - & $0.89(0.86,0.92)$ & $0.89(0.86,0.92)$ & $0.88(0.84,0.91)$ & $<0.0001$ \\
\hline Age & - & - & $1.01(1.00,1.01)$ & $1.01(1.01,1.01)$ & $1.00(1.00,1.01)$ & $<0.0001$ \\
\hline Marital status & - & - & & & & \\
\hline Married & - & - & ref & ref & ref & \\
\hline Single & - & - & $1.19(1.15,1.24)$ & $1.20(1.15,1.25)$ & $1.21(1.16,1.26)$ & $<0.0001$ \\
\hline Widowed & - & - & $1.18(1.12,1.23)$ & $1.18(1.13,1.24)$ & $1.24(1.16,1.32)$ & $<0.0001$ \\
\hline Divorced/separated & - & - & $1.15(1.10,1.21)$ & $1.15(1.10,1.21)$ & $1.20(1.13,1.26)$ & $<0.0001$ \\
\hline Not known & - & - & $0.93(0.81,1.07)$ & $0.94(0.82,1.07)$ & $0.97(0.83,1.13)$ & 0.714 \\
\hline \multicolumn{7}{|l|}{ IRSD } \\
\hline 1st quintile - most disadvantaged & - & - & ref & ref & ref & \\
\hline 2nd quintile & - & - & $0.95(0.91,0.99)$ & $0.95(0.91,0.99)$ & $0.95(0.90,1.00)$ & 0.061 \\
\hline 3rd quintile & - & - & $0.94(0.90,0.99)$ & $0.94(0.90,0.99)$ & $0.94(0.90,0.99)$ & $<0.05$ \\
\hline 4th quintile & - & - & $0.92(0.87,0.97)$ & $0.93(0.87,0.98)$ & $0.94(0.87,0.98)$ & 0.051 \\
\hline $\begin{array}{l}\text { 5th quintile - least } \\
\text { disadvantaged }\end{array}$ & - & - & $0.88(0.82,0.94)$ & $0.88(0.82,0.94)$ & $0.80(0.74,0.87)$ & $<0.0001$ \\
\hline \multicolumn{7}{|l|}{ ARIA } \\
\hline Highly Accessible & - & - & ref & ref & ref & \\
\hline Accessible & - & - & $0.93(0.89,0.97)$ & $0.93(0.89,0.97)$ & $0.94(0.90,0.98)$ & $>0.01$ \\
\hline Moderately Accessible & - & - & $0.88(0.83,0.93)$ & $0.88(0.83,0.93)$ & $0.86(0.81,0.92)$ & $<0.0001$ \\
\hline Remote / Very Remote & - & - & $0.67(0.61,0.73)$ & $0.67(0.61,0.73)$ & $0.65(0.59,0.72)$ & $<0.0001$ \\
\hline \multicolumn{7}{|l|}{ Charlson Index score } \\
\hline 0 & - & - & ref & ref & ref & \\
\hline 1 & - & - & $1.43(1.38,1.49)$ & $1.43(1.38,1.49)$ & $1.46(1.40,1.52)$ & $<0.0001$ \\
\hline $2+$ & - & - & $1.63(1.57,1.70)$ & $1.63(1.57,1.69)$ & $1.69(1.62,1.77)$ & $<0.0001$ \\
\hline
\end{tabular}

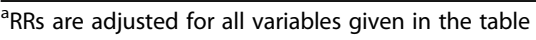

sample such that the distribution of selection confounders was similar to those that died during admission, however there may have been unmeasured confounders which biased the results. Caution should also be used in interpreting data on unplanned readmission as these data do not differentiate between avoidable and unavoidable unplanned readmissions, and therefore inevitably includes some readmissions which are appropriate and unavoidable. Finally, while it is likely that some patients had readmissions prior to 2005, our retrospective cohort study design allows us to only examine admissions within a defined time period only.

\section{Conclusion}

Aboriginal people with chronic disease had a significantly higher risk of unplanned readmission or death compared with non-Aboriginal people, and there has been no significant change over the nine year period. It is 
critical that effective interventions to reduce unplanned readmissions for Aboriginal people are identified.

\section{Endnotes}

${ }^{1}$ The importance of using correct, respectful and appropriate terminology for Aboriginal and Torres Strait Islander people is acknowledged. In keeping with NSW Health recommendations and acknowledging that Aboriginal people are the original habitants of NSW, the term Aboriginal people will be used (NSW Health "Communicating positively: A guide to appropriate Aboriginal terminology", NSW Department of Health 2004).

\section{Additional file}

Additional file 1: ICD-10 codes. A list of ICD-10 codes for eligible chronic diseases for this retrospective cohort study. (DOCX 18 kb)

\section{Abbreviations \\ ABS: Australian Bureau of Statistics; APDC: NSW Admitted Patient Data Collection; ARIA: Accessibility/Remoteness Index of Australia; CCl: Charlson Co-morbidity Index; Cl: confidence interval; RR: relative risk; EDDC: Emergency Department Data Collection; GLM: generalised linear model; IRSD: Index of Relative Socio-economic Disadvantage; NSW: New South Wales; RBDM: NSW Registrar of Births, Deaths and Marriages}

\section{Acknowledgements}

We would like to acknowledge the traditional custodians of NSW, Australia, the Aboriginal people and pay our respects to the Elders past, present and future.

\section{Funding}

This study received funding from the Priority Research Centre for Health Behaviour, University of Newcastle. The funder had no role in the research study.

\section{Availability of data and materials}

The data that support the findings of this study (The Centre for Health Record Linkage linked NSW government administrative datasets) are available from NSW Health but restrictions apply to the availability of these data and so are not publicly available. Access to the data is available by application to the data custodians, NSW Health.

\section{Authors' contributions}

AJ, CO and MC contributed to the design of the study. AJ drafted the manuscript. $\mathrm{AJ}$ and $\mathrm{CO}$ conducted the analysis, with advice from JA, and TE prepared the datasets. JB, CO, MC, TE, R S-F and SE provided critical review of the manuscript. All authors contributed to the interpretation of findings, and have read and approved the final manuscript.

\section{Ethics approval and consent to participate}

The study was approved by the NSW Population \& Health Services Research Ethics Committee (HREC/15/CIPHS/18) and the NSW Aboriginal Health and Medical Research Council Ethics Committee (1090/15). The Ethics Committees granted a waiver of the usual requirement for the consent of the individual to the use of their health information in a research project, in line with the State Privacy Commissioner's Guidelines for Research and the Health Records and Information Privacy Act 2002 (NSW). The Centre for Health Record Linkage preserve privacy and maintain robust data governance. As researchers are only able to access de-identified linked data, the Centre for Health Record Linkage enable ethically approved research in the public interest to be carried out without consent.

\section{Consent for publication}

Not applicable.

\section{Competing interests}

The authors declare no competing interests.

\section{Publisher's Note}

Springer Nature remains neutral with regard to jurisdictional claims in published maps and institutional affiliations.

\section{Author details}

${ }^{1}$ Health Behaviour Research Collaborative, School of Medicine and Public Health, Faculty of Health and Medicine, University of Newcastle, Callaghan, NSW 2308, Australia. ${ }^{2}$ Priority Research Centre for Health Behaviour, University of Newcastle, Callaghan, NSW, Australia. ${ }^{3}$ Hunter Medical Research Institute, New Lambton Heights, NSW, Australia. ${ }^{4}$ CREDITSS-Clinical Research Design, Information Technology and Statistical Support Unit, Hunter Medical Research Institute, HMRI Building, New Lambton Heights, NSW, Australia. ${ }^{5}$ School of Medicine and Public Health, University of Newcastle, Callaghan, NSW 2308, Australia. ${ }^{6}$ Nunyara Aboriginal Health Unit, Central Coast Local Health District, Ward Street, Gosford, NSW, Australia.

Received: 3 August 2018 Accepted: 16 November 2018

Published online: 26 November 2018

\section{References}

1. Australian Institute of Health and Welfare: The health and welfare of Australia's Aboirginal and Torres Strait islander people: 2015. Cat. no: IHW 147. Canberra: AlHW; 2015

2. Vos T, Barker B, Begg S, Stanley L, Lopez AD. Burden of disease and injury in aboriginal and Torres Strait islander peoples: the indigenous health gap. Int J Epidemiol. 2009;38:470-7.

3. Bureau of Health Information: Chronic disease care: another piece of the picture. 2(2). Sydney (NSW); 2012

4. Dennis SM, Zwar N, Griffiths R, Roland M, Hasan I, Powell Davies G, Harris M. Chronic disease management in primary care: from evidence to policy. Med J Aust. 2008;188:S53-6.

5. Rothman AA, Wagner EH. Chronic illness management: what is the role of primary care? Ann Intern Med. 2003;138:256-61.

6. Hansen LO, Young RS, Hinami K, Leung A, Williams MV. Interventions to reduce 30-day rehospitalization: a systematic review. Ann Intern Med. 2011; 155:520-8.

7. Jack BW, Chetty VK, Anthony D, Greenwald JL, Sanchez GM, Johnson AE, Forsythe SR, O'Donnell JK, Paasche-Orlow MK, Manasseh C, et al. A reengineered hospital discharge program to decrease RehospitalizationA randomized trial. Ann Intern Med. 2009;150:178-87.

8. Australian Council on Healthcare Standards: Australasian clinical indicator report: 15th Edition 2006-2013. Sydney, Australia; ACHS; 2014; 2014.

9. Centre for Epidemiology and Evidence. The health of aboriginal people of NSW: report of the chief health officer. Sydney: NSW Ministry of Health; 2012

10. Vest JR, Gamm LD, Oxford BA, Gonzalez MI, Slawson KM. Determinants of preventable readmissions in the United States: a systematic review. Implement Sci. 2010;5:88

11. Jencks SF, Williams MV, Coleman EA. Rehospitalizations among patients in the Medicare fee-for-service program. N Engl J Med. 2009;360:1418-28.

12. Robert Wood Foundation. The revolving door: a report on U.S. Hospital Readmissions. The Dartmouth Institute for Health Policy and Clinical Practice; 2013

13. Brand C, Sundararajan V, Jones C, Hutchinson A, Campbell D. Readmission patterns in patients with chronic obstructive pulmonary disease, chronic heart failure and diabetes mellitus: an administrative dataset analysis. Intern Med J. 2005;35:296-9.

14. Weinberger M, Oddone EZ, Henderson WG. Does increased access to primary care reduce hospital readmissions? Veterans affairs cooperative study group on primary care and hospital readmission. N Engl J Med. 1996:334:1441-7.

15. Australian Institute of Health and Welfare: Australian hospital statistics 2012 13. Health services series no. 54. Cat. no. HSE 145. Canberra: AlHW; 2014

16. McLean R, Mendis K, Canalese J. A ten-year retrospective study of unplanned hospital readmissions to a regional Australian hospital. Aust Health Rev. 2008;32:537-47.

17. Centre for Health Record Linkage: [http://www.cherel.org.au]. Accessed 1 Oct 2018. 
18. Commonwealth Department of Health and Aged Care. Revised Edition: Measuring remoteness: accessibility/remoteness index of Australia (ARIA). Occasional papers: new series Number14. Canberra, Australia; 2001.

19. Australian Bureau of Statistics: IRSD: census of population and housing: socio-economic indexes for areas (SEIFA). ABS, Australia. Accessed 1 November 2017. 2011.

20. Charlson ME, Pompei P, Ales KL, Mackenzie CR. A new method of classifying prognostic comorbidity in longitudinal studies: development and validation. J Chronic Dis. 1987:40:373-83.

21. Ye Y, Kaskutas LA. Using propensity scores to adjust for selection bias when assessing the effectiveness of alcoholics anonymous in observational studies. Drug Alcohol Depend. 2009;104:56-64.

22. StataCorp.: Stata Statistical Software: Release 11. College Station, TX: StataCorp LP. 2009.

23. Banham D, Chen T, Karnon J, Brown A, Lynch J. Sociodemographic variations in the amount, duration and cost of potentially preventable hospitalisation for chronic conditions among aboriginal and non-aboriginal Australians: a period prevalence study of linked public hospital data. BMJ Open. 2017;7:e017331.

24. Trivedi AN, Bailie R, Bailie J, Brown A, Kelaher M. Hospitalizations for chronic conditions among indigenous Australians after medication copayment reductions: the closing the gap copayment incentive. J Gen Intern Med. 2017:32:501-7.

25. Li SQ, Gray NJ, Guthridge SL, Pircher SL. Avoidable hospitalisation in aboriginal and non-aboriginal people in the Northern Territory. Med J Aust. 2009;191:411.

26. Calvillo-King L, Arnold D, Eubank K, Lo M, Yunyongying P, Stieglitz H, Halm EA. Impact of social factors on risk of readmission or mortality in pneumonia and heart failure: systematic review. J Gen Intern Med. 2013;28:269-82.

27. Joynt KE, Orav EJ, Jha AK. Thirty-day readmission rates for Medicare beneficiaries by race and site of care. JAMA. 2011;305:675-81.

28. Laditka JN, Laditka SB, Mastanduno MP. Hospital utilization for ambulatory care sensitive conditions: health outcome disparities associated with race and ethnicity. Soc Sci Med. 2003;57:1429-41.

29. Katzenellenbogen JM, Miller LJ, Somerford P, McEvoy S, Bessarab D. Strategic information for hospital service planning: a linked data study to inform an urban aboriginal health liaison officer program in Western Australia. Aust Health Rev. 2015;39:429-36.

30. Taylor KP, Thompson SC, Smith JS, Dimer L, Ali M, Wood MM. Exploring the impact of an aboriginal health worker on hospitalised aboriginal experiences: lessons from cardiology. Aust Health Rev. 2009;33:549-57.

31. Jayakody A, Passmore E, Oldmeadow C, Bryant B, Carey M, Simons E, Cashmore A, Maher L, Hennessey K, Bunfield J, et al. The impact of telephone follow up on adverse events for aboriginal people with chronic disease in New South Wales, Australia: a retrospective cohort study. Int J Equity Health. 2018;17.

32. Kossovsky MP, Sarasin FP, Chopard P, Louis-Simonet M, Sigaud P, Perneger TV, Gaspoz JM. Relationship between hospital length of stay and quality of care in patients with congestive heart failure. Qual Saf Health Care. 2002;11: 219-23.

33. Katzenellenbogen JM, Sanfilippo FM, Hobbs MS, Knuiman MW, Bessarab D, Durey A, Thompson SC. Voting with their feet--predictors of discharge against medical advice in aboriginal and non-aboriginal ischaemic heart disease inpatients in Western Australia: an analytic study using data linkage. BMC Health Serv Res. 2013;13:330.

Ready to submit your research? Choose BMC and benefit from:

- fast, convenient online submission

- thorough peer review by experienced researchers in your field

- rapid publication on acceptance

- support for research data, including large and complex data types

- gold Open Access which fosters wider collaboration and increased citations

- maximum visibility for your research: over $100 \mathrm{M}$ website views per year

At BMC, research is always in progress.

Learn more biomedcentral.com/submissions 